\title{
Anti-cancer Effects of a Novel Quinoline Derivative 83b1 on Human Esophageal Squamous Cell Carcinoma through Down-Regulation of COX-2 mRNA and PGE2
}

\author{
Ivan Ho Yuen Pun, BSC ${ }^{1}$ \\ Dessy Chan, BSC ${ }^{1}$ \\ Sau Hing Chan, $\mathrm{PhD}^{1}$ \\ Po Yee Chung, $\mathrm{BSC}^{\dagger}$ \\ Yuan Yuan Zhou, MSc ${ }^{1}$ \\ Simon Law, MBBChir, MS² \\ Alfred King Yin Lam, MD, PhD ${ }^{3}$ \\ Chung Hin Chui, $\mathrm{PhD}^{4}$ \\ Albert Sun Chi Chan, $\mathrm{PhD}^{5}$ \\ Kim Hung Lam, $\mathrm{PhD}^{1}$ \\ Johnny Cheuk On Tang, PhD'
}

\author{
${ }^{1}$ State Key Laboratory of Chirosciences, \\ Lo Ka Chung Centre for Natural Anti-cancer \\ Drug Development, Department of Applied \\ Biology and Chemical Technology, \\ The Hong Kong Polytechnic University, \\ Hong Kong, ${ }^{2}$ Department of Surgery, \\ Li Ka Shing Faculty of Medicine, \\ The University of Hong Kong, Hong Kong, \\ China, ${ }^{3}$ Department of Pathology, \\ Griffith Medical School and Griffith Health \\ Institute, Griffith University, Gold Coast, \\ Queensland, Australia, ${ }^{4}$ Clinical Division, \\ School of Chinese Medicine, Hong Kong \\ Baptist University, Hong Kong, \\ ${ }^{5}$ Sun Yat Sen University, School of \\ Pharmaceutical Sciences, Guangzhou, China
}

Correspondence: Johnny Cheuk On Tang, PhD Y1202, Department of Applied Biology and Chemical Technology, The Hong Kong Polytechnic University, Hung Hom, Hong Kong Tel: 852-3400-8727

Fax: 852-3013-8935

E-mail: dr-johnny.tang@polyu.edu.hk

Received May 4, 2016

Accepted June 7, 2016

Published Online July 18, 2016

\section{Purpose}

$83 \mathrm{~b} 1$ is a novel quinoline derivative that has been shown to inhibit cancer growth in human esophageal squamous cell carcinoma (ESCC). This study was conducted to comprehensively evaluate the cytotoxic effects of 83b1 on a series of ESCC cell lines and investigate the mechanisms by which $83 \mathrm{~b} 1$ suppresses cancer growth based on molecular docking analysis.

\section{Materials and Methods}

A series of ESCC and nontumor immortalized cell lines were exposed to $83 \mathrm{~b} 1$ and cisplatin (CDDP) in a dose-dependent manner, and the cytotoxicity was examined by a MTS assay kit. Prediction of the molecular targets of $83 \mathrm{~b} 1$ was conducted by molecular docking analysis. Expression of cyclooxygenase 2 (COX-2) mRNA and COX-2-derived prostaglandin $\mathrm{E}_{2}$ $\left(\mathrm{PGE}_{2}\right)$ were measured by quantitative real-time polymerase chain reaction and enzymelinked immuno-sorbent assay, respectively. In vivo anti-tumor effect was determined using a nude mice xenografted model transplanted with an ESCC cell line, KYSE-450.

\section{Results}

$83 b 1$ showed the significant anti-cancer effects on all ESCC cell lines compared to CDDP; however, 83b1 revealed much lower toxic effects on non-tumor cell lines than CDDP. The predicted molecular target of $83 \mathrm{~b} 1$ is peroxisome proliferator-activated receptor delta (PPARס), which is a widely known oncoprotein. Additionally the expression of COX-2 mRNA and COX-2-derived PGE 2 were down-regulated by $83 \mathrm{~b} 1$ in a dose-dependent manner in ESCC cell lines. Furthermore, $83 \mathrm{~b} 1$ was shown to significantly reduce the tumor size in nude mice xenograft.

\section{Conclusion}

The results of this study suggest that the potential anti-cancer effects of $83 \mathrm{~b} 1$ on human esophageal cancers occur through the possible oncotarget, PPARס, and down-regulation of the cancer related genes and molecules. 


\section{Introduction}

Esophageal cancer is the eighth most prevalent cancer and the sixth leading cause of cancer deaths throughout the world [1]. At present, the treatments for esophageal cancers include surgical resection, radiotherapy and chemotherapy $[2,3]$. However, the curative effects of the existing treatments appear to be insufficient, as reflected by the sub-optimal 5 -year survival rate (almost less than 20\%) and the observed toxicities of the anti-cancer drugs $[3,4]$. Therefore, identification of new anti-cancer drugs for treatment of esophageal and other cancers has become a crucial issue.

Quinoline derivatives, which have been widely reported to possess a broad range of pharmaceutical activities, can be isolated from different plant sources [5]. The first commonly known natural quinoline compound, 4-hydroxy-6-methoxyquinoline-2-carboxylic acid (Fig. 1), was extracted from Ephedra pachyclada ssp. sinaica, which has been widely used in traditional herbal medicine against allergy, inflammation, microbial and cardiovascular diseases, and cancer [6,7]. 8-Hydroxyquinoline and its derivatives were also reported as natural products such as those isolated from the roots of Centaurea diffusa with phytotoxic activities [8] and Suaeda corniculata with anti-bacterial and anti-fungal activities [9]. Therefore, researchers have further improved the efficacy and potency of quinoline by modifying its structure. Our previous findings also revealed that the 8-hydroxyquinoline derivatives showed relatively promising in vitro and in vivo anti-cancer effects [5], as well as anti-bacterial effects, implying the importance of the 8-hydroxyl group for their biological actions [10].

Peroxisome proliferator-activated receptor (PPAR), a member of the nuclear hormone receptor superfamily, exists as three main subtypes, PPAR $\alpha$, PPAR $\gamma$, and PPAR $\delta$ (also known as PPAR $\beta$ ). These receptors can also act as ligandactivated transcription factors. PPAR $\delta$ is ubiquitously expressed in most human tissues, and many studies have

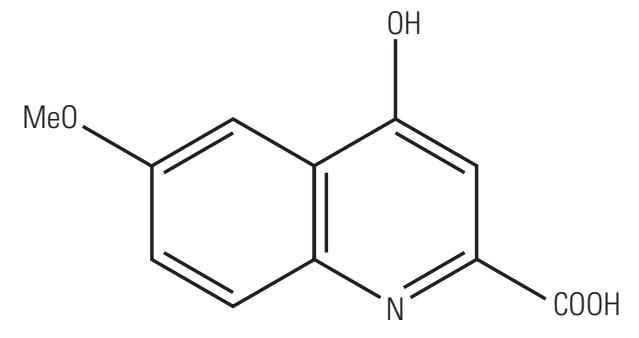

Fig. 1. Structure of 4-hydroxy-6-methoxyquinoline-2-carboxylic acid. shown that PPAR $\delta$ is highly overexpressed in tumor cells relative to non-tumor cells. Moreover, it has been shown to be involved in cell differentiation and inflammation, which are highly related to tumor development [11]. In the ligandbound state, PPAR $\delta$ can bind to an activator and associate with the peroxisome proliferated response element to promote gene transcription. The potential pathways related to the PPAR $\delta$ for inducing tumor growth include the cyclooxygenase 2 (COX-2) [12,13]. It has also been reported that there are solid correlations among the pathways of PPAR $\delta$, overexpression of COX-2 and tumor development [12]. Thus, targeting PPAR $\delta$ forms a very important direction for exploring novel anti-cancer agents.

Cyclooxygenase, which is also known as prostaglandin $\mathrm{H}$ synthase, exists as two main isoforms, COX-1 and COX-2. COX-1 is constitutively expressed in most mammalian cells and has functions such as regulation of renal blood flow and platelet aggregation [14]. However, COX-2 is inducible and usually overexpressed in gastrointestinal cancers, including esophageal cancer $[15,16]$. Previous studies showed that COX-2 is highly related to tumorigenic events involving cell proliferation, invasion, apoptosis, inflammation and angiogenesis $[17,18]$. Moreover, it has been shown that COX-2 derived prostaglandin $\mathrm{E}_{2}\left(\mathrm{PGE}_{2}\right)$ is one of the potential products that promotes development of tumors [19]. $\mathrm{PGE}_{2}$ is a well-known molecule that participates in tumorigenesis by binding to complementary EP2 and EP4 receptors on cell membranes [16].

In this study, a novel quinoline derivative (8-(4-(trifluoromethyl)benzyloxy)-1,2,3,4-tetrahydro-2-methylquin-oline, named as 83b1) was examined through in vitro and in vivo anti-cancer tests on esophageal cancer cell lines. The associated mechanisms were also investigated based on molecular docking analysis to reveal PPAR $\delta$ as a target in cancer treatment.

\section{Materials and Methods}

\section{Reagents and materials}

Cell culture medium RPMI-1640, F-12, Dulbecco's modified Eagle's medium, minimum essential medium $\alpha(\mathrm{MEM} \alpha)$, keratinocyte serum-free medium (KSFM), fetal bovine serum (FBS), and penicillin/streptomycin were purchased from Life Technologies (Carlsbad, CA). 83b1 was completely dissolved in dimethylsulfoxide (DMSO). 


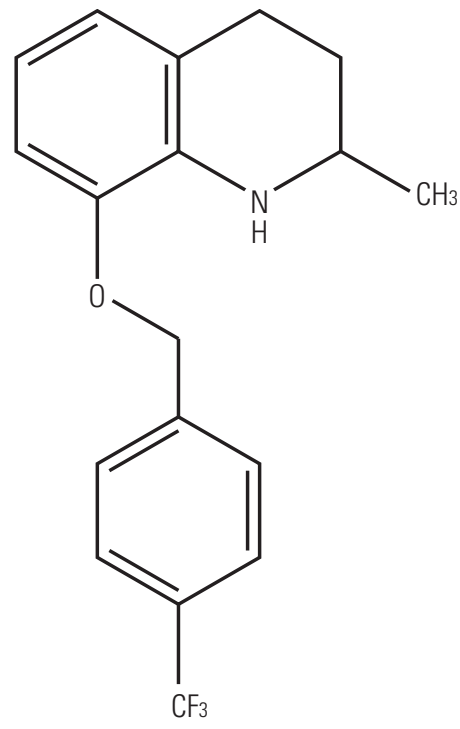

Fig. 2. Structure of $83 b 1$.

\section{Synthesis of $83 \mathrm{~b} 1$ with electrospray ionization mass spec- trometry and ${ }^{1} \mathrm{H}-\mathrm{NMR}$ examination}

8-(4-(Trifluoromethyl)benzyloxy)-1,2,3,4-tetrahydro2-methylquinoline (compound 83b1) (Fig. 2) was prepared according to our previously reported method of asymmetric hydrogenation on 8-(4-(trifluoromethyl)-benzyloxy)-2-methylquinoline, which was obtained through nucleophilic substitution of commercially available 8-hydroxy-2-methylquinoline (Sigma-Aldrich, St. Louis, MO) [20]. The structure and purity of $83 \mathrm{~b} 1$ was examined through ${ }^{1} \mathrm{H}-\mathrm{NMR}$ and liquid chromatography mass spectrometry (LC-MS).

$83 \mathrm{~b} 1$, which appeared as a white solid, was dissolved in $\mathrm{CDCl}_{3}$ completely and examined by ${ }^{1} \mathrm{H}-\mathrm{NMR}$ (Supplementary Fig. S1). Upon analysis the following spectrum was reported: ${ }^{1} \mathrm{H}-\mathrm{NMR}\left(500 \mathrm{MHz}, \mathrm{CDCl}_{3}\right): \delta 1.30(\mathrm{~d}, 3 \mathrm{H}, \mathrm{J}=6.0$ $\mathrm{Hz}), 1.63-1.72(\mathrm{~m}, 1 \mathrm{H}), 1.95-1.98(\mathrm{~m}, 1 \mathrm{H}), 2.75-2.79(\mathrm{~m}, 1 \mathrm{H})$, 2.85-2.90 (m, 1H), 3.39-3.43 (m, 1H), 4.17 (bs, 1H), $5.13(\mathrm{q}, 2 \mathrm{H}$, $\mathrm{J}=12.5 \mathrm{~Hz}), 6.54(\mathrm{t}, 1 \mathrm{H}, \mathrm{J}=8.0 \mathrm{~Hz}), 6.68(\mathrm{~d}, 1 \mathrm{H}, \mathrm{J}=8.0 \mathrm{~Hz}), 6.72$ $(\mathrm{d}, 1 \mathrm{H}, \mathrm{J}=7.5 \mathrm{~Hz}), 7.55(\mathrm{~d}, 2 \mathrm{H}, \mathrm{J}=8.0 \mathrm{~Hz}), 7.66(\mathrm{~d}, 2 \mathrm{H}, \mathrm{J}=8.5$ $\mathrm{Hz}$ ). These findings are consistent with the expected structure shown in Fig. 2. The purity and molecular weight of the synthesized $83 \mathrm{~b} 1$ were further examined by LC-MS (Supplementary Fig. S2). According to the data obtained, there were three peaks separated in different retention periods. The peaks were analyzed by electrospray ionization mass spectrometry (Supplementary Fig. S3), and the peak comprising $99.7 \%$ total area showed a $\mathrm{m} / \mathrm{z}$ ratio of $83 \mathrm{~b} 1$ (molecular weight $321 \mathrm{~g} / \mathrm{mol}$ ), whereas the other two peaks comprising $0.3 \%$ total area were found to be impurities. Therefore, the purity of $83 \mathrm{~b} 1$ is very high.

\section{Cell lines and culture conditions}

One of the esophageal squamous cell carcinoma (ESCC) cell lines of Hong Kong Chinese origin, SLMT-1 [21], was kindly provided by Professor Gopesh Srivastava of the Department of Pathology, the University of Hong Kong. The other two ESCC cell lines of Hong Kong Chinese origin, including HKESC-2 and HKESC-4, and three ESCC cell lines of Japanese origin, including KYSE-150, KYSE-450, and KYSE-520 [22], were purchased from DSMZ (Braunschweig, Germany). Two non-tumor esophageal epithelial cell lines including NE-1 [23] and NE-3 [24] were kindly provided by Professor George S. W. Tsao from the Department of Anatomy, the University of Hong Kong. A human skin cell line, HEK001, was purchased from the American Type Culture Collection (ATCC) and cultured as suggested. The culture medium for KYSE-150 and KYSE-450 was RPMI with $45 \%$ F-12 and 10\% FBS, that for KYSE-520 was RPMI with $10 \%$ FBS, that for SLMT-1, HKESC-2, and HKESC-4 was MEM $\alpha$ with $10 \%$ FBS, and NE-1, NE-3, and HEK001 were cultured on KSFM with complementary supplements. All media were supplemented with 100 units / $\mathrm{mL}$ penicillin $\mathrm{G}$ and $100 \mu \mathrm{g} / \mathrm{mL}$ streptomycin, and all cell lines mentioned above were cultured at $37^{\circ} \mathrm{C}$ in a humidified incubator with $5 \% \mathrm{CO}_{2}$.

\section{In vitro cytotoxicity studies by MTS}

3-(4,5-Dimethylthiazol-2-yl)-5-(3-carboxymethoxyphenyl)2-(4-sulfophenyl)-2H-tetrazolium (MTS) assay was performed to evaluate the growth inhibitory effects of $83 \mathrm{~b} 1$ on the six described ESCC cell lines and three immortalized non-tumor cell lines using the CellTiter96 AQueous One Solution (Promega, Madison, WI) for cell proliferation assay as previously reported [25]. In addition, a widely used anticancer drug, cisplatin (CDDP), was used as a positive control [26]. Briefly, $5 \times 10^{3}$ cells were seeded onto each well of the 96 well plate and allowed to grow for 24 hours. After incubation for 24 hours, different concentrations of $83 \mathrm{~b} 1$ and CDDP $(0,1.5625,3.125,6.25,12.5,25$, and $50 \mu \mathrm{g} / \mathrm{mL})$ were added as the treatment. The results were recorded after 72 hours of the treatments using a micro-plate reader to measure the absorbance at $495 \mathrm{~nm}$.

\section{Molecular docking analysis}

Evaluation of the possible molecular binding targets of 83b1 was conducted based on the similarity ensemble approach (SEA) using the search engine available from http:// sea.bkslab.org. The binding of $83 \mathrm{~b} 1$ to the protein targets was predicted based on molecular structures matched against the ChEMBL medicinal chemistry database version 
A
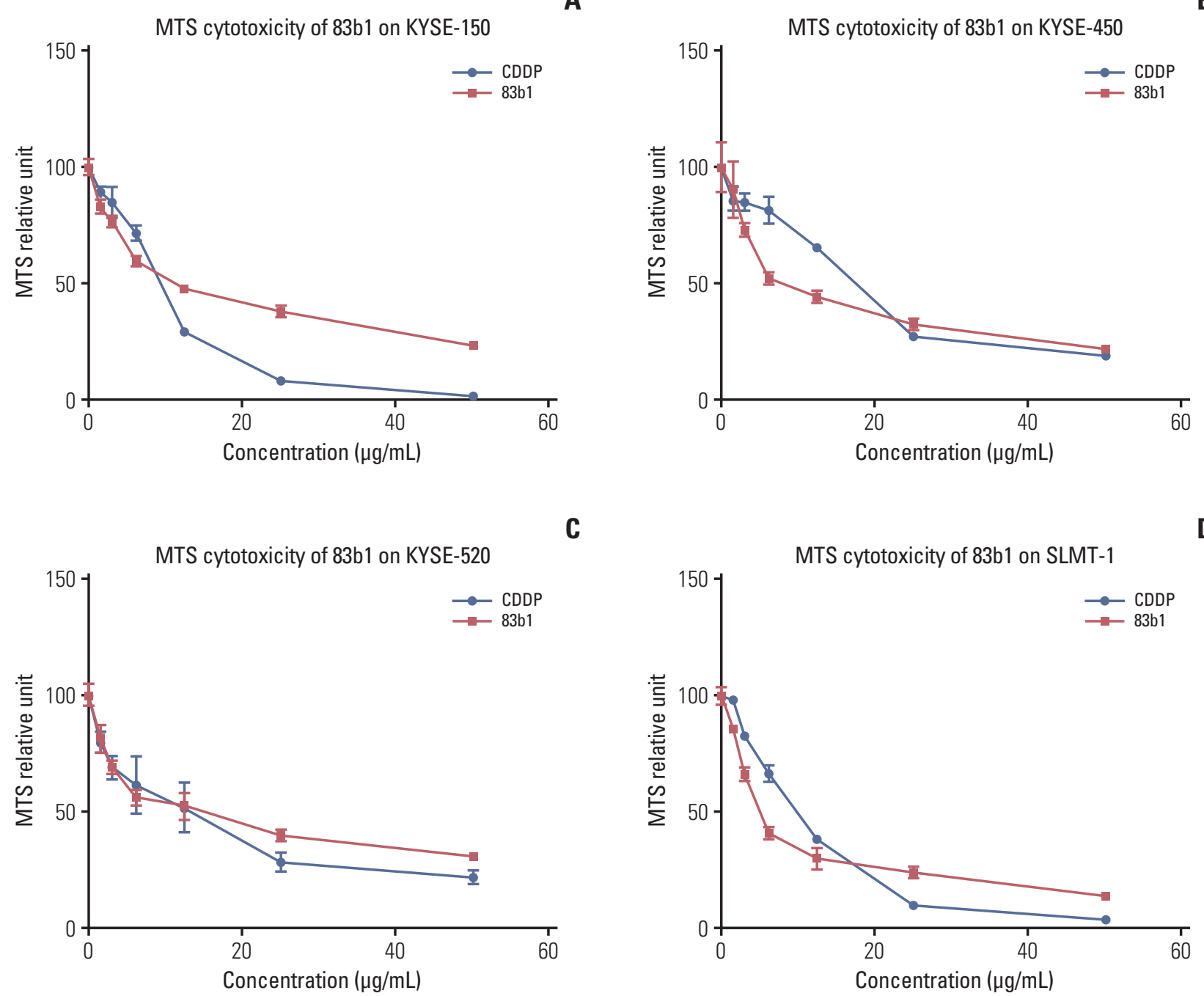

C

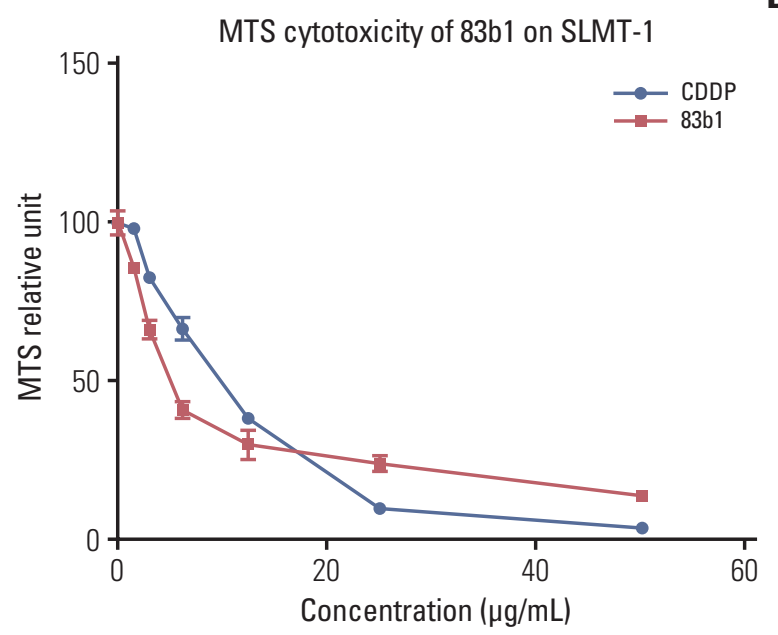

$\mathbf{E}$
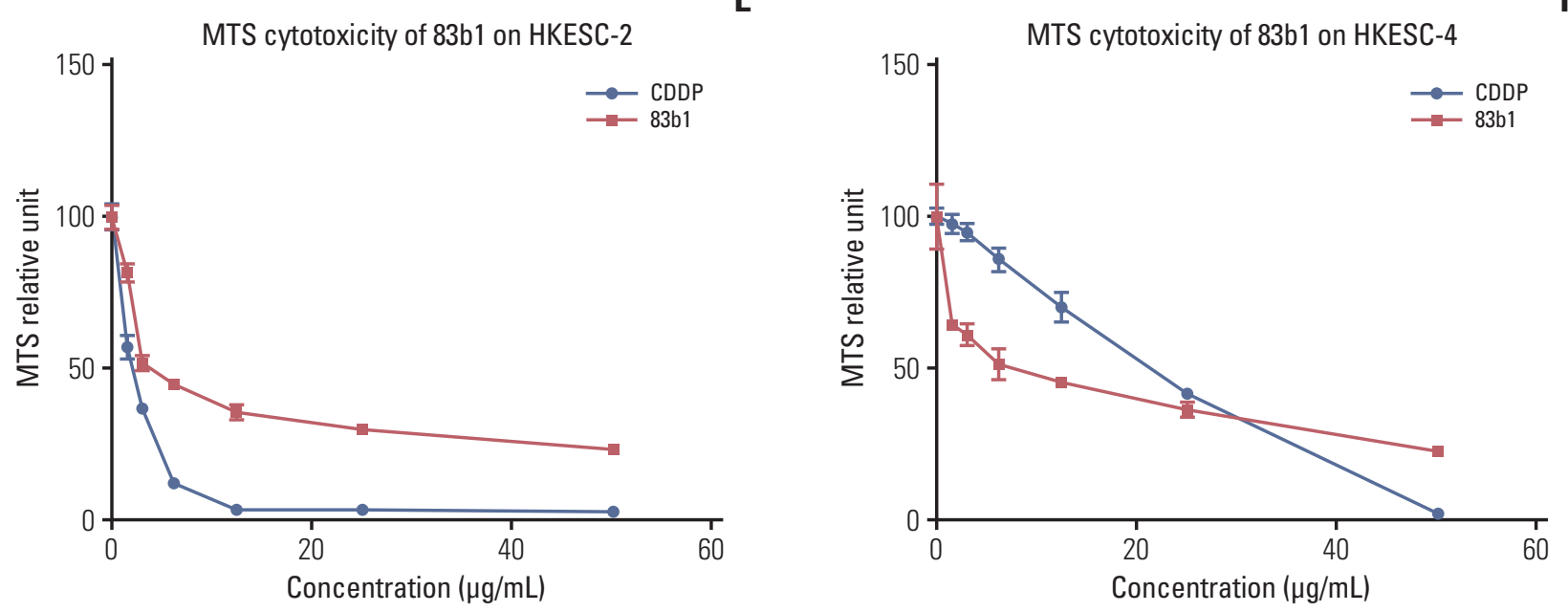

Fig. 3. (A-I) Inhibitory effects of $83 \mathrm{~b} 1$ on ESCC and non-tumor cell lines examined by MTS cytotoxicity assay. ESCC, esophageal squamous cell carcinoma; MTS, 3-(4,5-dimethylthiazol-2-yl)-5-(3-carboxymethoxyphenyl)-2-(4-sulfophenyl)$2 \mathrm{H}$-tetrazolium. (Continued to the next page) 

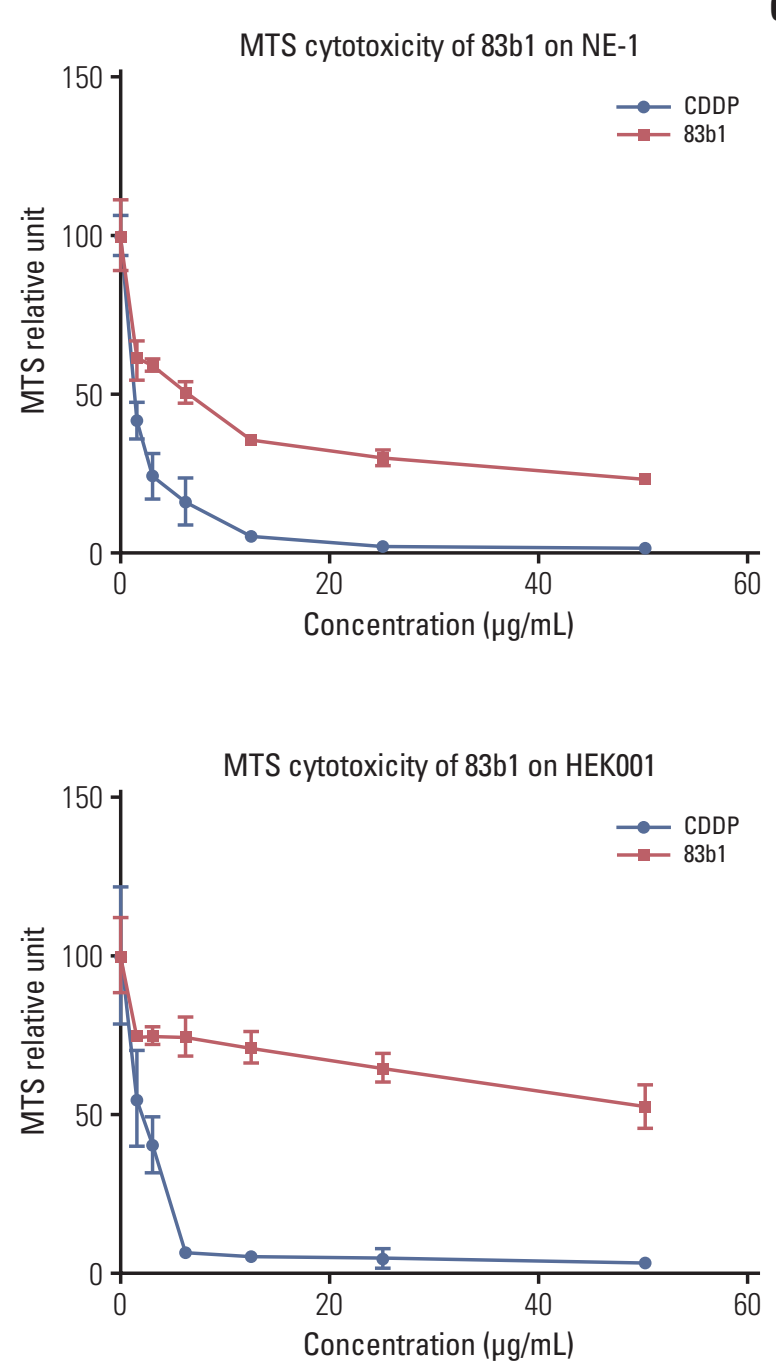

Fig. 3. (Continued from the previous page)

12 as previous described [27]. Another docking program involving the molecular docking server (http:// www.dockingserver.com/web) was used to determine the binding affinity of $83 \mathrm{~b} 1$ to its predicted target relative to the natural ligand of the target. The docking calculations were conducted using DockingServer [28].

\section{Reverse transcription polymerase chain reaction and quantitative real-time polymerase chain reaction}

The gene expression levels of COX-2 in the four ESCC cell lines (KYSE-150, KYSE-450, SLMT-1, and HKESC-4) with the treatments of $83 \mathrm{~b} 1$ were studied by quantitative real-time polymerase chain reaction (qPCR). Approximately $1 \times 10^{6}$ cells from each cell line were evenly separated into eight

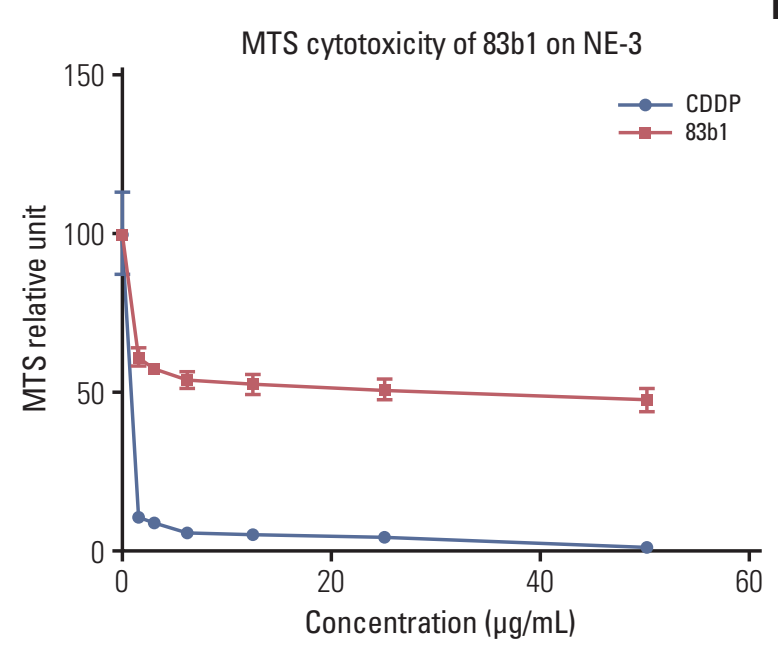

H 
Table 1. Summary of inhibitory effects $\left(\mathrm{MTS}_{50}\right)$ of $83 \mathrm{~b} 1$ on ESCC and non-tumor cell lines

\begin{tabular}{|c|c|c|}
\hline & \multicolumn{2}{|c|}{$\mathrm{MTS}_{50}(\mu \mathrm{g} / \mathrm{mL})$ for $72 \mathrm{~h}$} \\
\hline & $83 b 1$ & CDDP \\
\hline \multicolumn{3}{|c|}{ ESCC cell line } \\
\hline KYSE-150 & 11.72 & 8.58 \\
\hline KYSE-450 & 9.71 & 15.85 \\
\hline KYSE-520 & 12.47 & 10.08 \\
\hline SLMT-1 & 5.87 & 8.99 \\
\hline HKESC-2 & 5.94 & 1.98 \\
\hline HKESC-4 & 6.87 & 18.81 \\
\hline \multicolumn{3}{|c|}{ Non-tumor cell line } \\
\hline NE-1 & 5.15 & 1.03 \\
\hline NE-3 & $>50$ & 0.02 \\
\hline HEK001 & 133.30 & 1.94 \\
\hline
\end{tabular}

ESCC, esophageal squamous cell carcinoma; CDDP, cisplatin.

entific, Waltham, MA). Glyceraldehyde 3-phosphate dehydrogenase (GAPDH) was used as an internal control to normalize the quantity of cDNA synthesized from all cell lines. The specific primers for COX-2 were as follows: $5^{\prime}$-CCA GCA CTT CAC GCA TCA GT-3' (forward) and 5'-ACG CTG TCT AGC CAG AGT TTC AC-3' (reverse) [29] and the specific primers for GAPDH were as follows: $5^{\prime}$-AAA TCA AGT GGG GCG ATG CTG-3' (forward) and 5'-GCA GAG ATG ATG ACC CTT TTG-3' (reverse) [30].

\section{Enzyme-linked immuno-sorbent assay}

The effects of $83 \mathrm{~b} 1$ on the production of $\mathrm{PGE}_{2}$ in the cell lines (KYSE-150, KYSE-450, and SLMT-1) were examined using an enzyme-linked immuno-sorbent assay (ELISA) kit (Cayman, Ann Arbor, MI). Approximately $1 \times 10^{6}$ cells from each cell line were evenly separated into eight replicates and then seeded for 24 hours. Three different concentrations of $83 \mathrm{~b} 1(5,10$, and $20 \mu \mathrm{g} / \mathrm{mL})$ and a negative control $(0.05 \%$ DMSO) were used to incubate the cells for 48 hours. The culture medium was then removed for quantitative determina- tion of $\mathrm{PGE}_{2}$ with reference to the standard curve according to the manufacturer's instructions.

\section{In vivo studies of $83 \mathrm{~b} 1$ in nude-mice xenograft with KYSE-450}

Athymic nude mice 4 weeks of age were purchased from the State Key Laboratory of Chinese Medicine and Molecular Pharmacology (Shenzhen, China), the Hong Kong Polytechnic University. All procedures were approved by the ethics committee. Approximately $5 \times 10^{6}$ KYSE-450 cells were injected subcutaneously into the mid-dorsal region of eight athymic nude mice. Tumors were allowed to grow without treatment until a volume of $150 \mathrm{~mm}^{3}$ was reached. The ten nude mice were randomly divided into two groups. 83b1 was then injected into five mice intraperitoneally at 10 $\mathrm{mg} / \mathrm{kg} /$ day, while the rest of the mice were used as the vehicle control. Tumor volumes were measured daily with calipers and calculated as previously described [25].

\section{Statistical analyses}

All values expressed in the charts are shown as the mean \pm standard error of means, and statistical analyses were conducted using the statistic program Prism ver. 5. A p-value of $<0.05$ was considered statistically significant.

\section{Results}

\section{In vitro cytotoxicity studies}

The inhibitory effects of $83 \mathrm{~b} 1$ on the described ESCC cell lines and immortalized non-tumor cell lines were examined by MTS cytotoxicity assay. As shown in Fig. 3A-F, 83b1 showed comparable inhibitory effect on all ESCC cell lines with CDDP in a dose-dependent manner. The inhibitory effects are summarized in terms of MTS $_{50}$ (50\% reduction of MTS signals compared with the vehicle control) in Table 1. In addition, $83 \mathrm{~b} 1$ showed significantly weaker cytotoxic

Table 2. Two human proteins with the highest ranking for ligand-binding to 83b1

\begin{tabular}{lccc} 
Reference name & Species & Expected value & Maximum target complementary value \\
$\begin{array}{c}\text { Peroxisome proliferator- } \\
\text { activated receptor delta }\end{array}$ & Human & $4.01 \mathrm{e}^{-7}$ & 0.36 \\
$\begin{array}{l}\text { Protein-tyrosine } \\
\text { phosphatase 1C }\end{array}$ & Human & $2.38 \mathrm{e}^{-8}$ & 0.33 \\
\hline
\end{tabular}



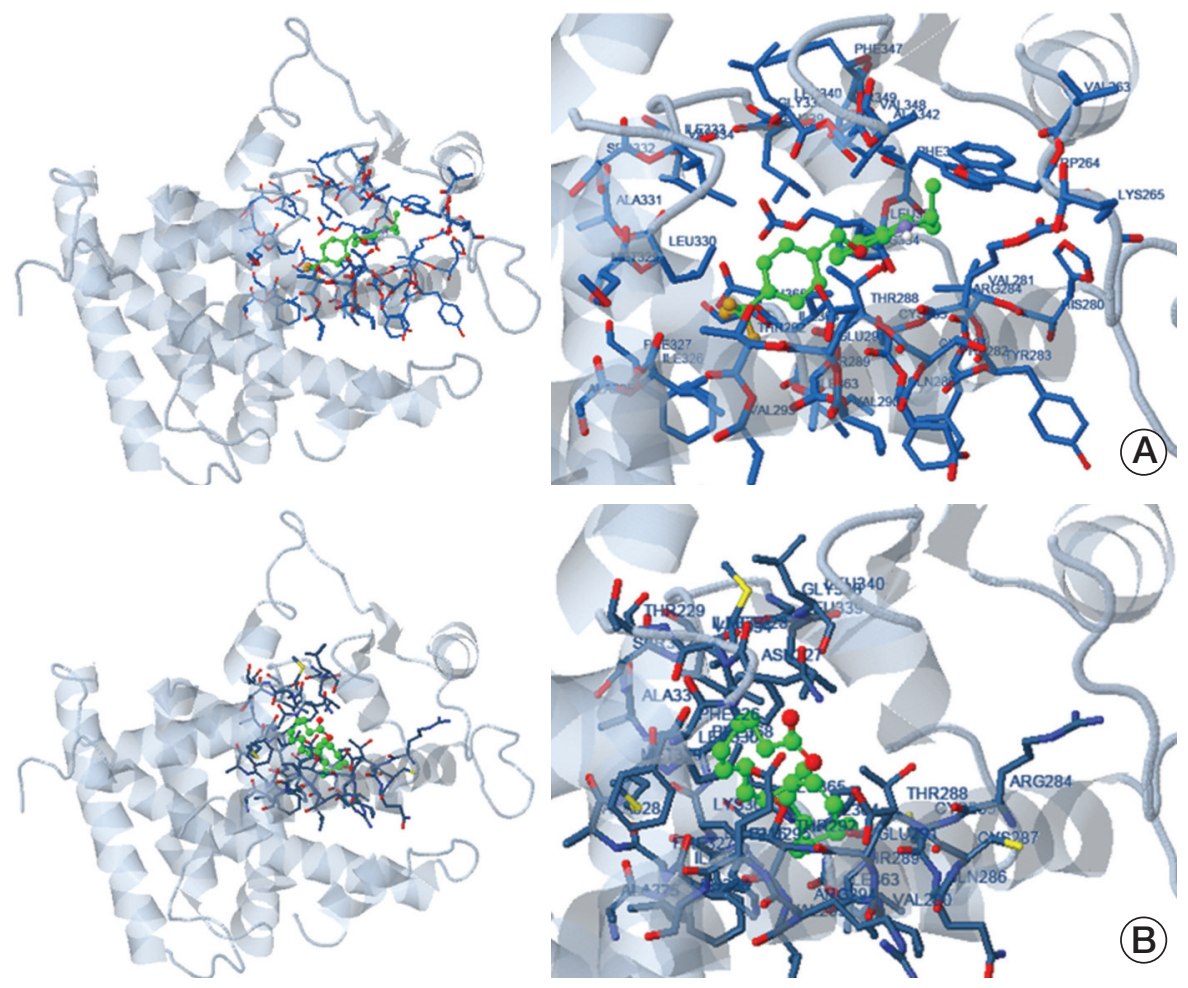

Fig. 4. Molecular docking of $83 \mathrm{~b} 1$ (A) and arachidonic acid (B) on peroxisome proliferator-activated receptor $\delta$.

effects on NE-1, NE-3, and HEK001 than CDDP (Table 1, Fig. 3G-I).

\section{Molecular docking analysis}

The SEA, which has been shown to be an important step for predicting possible drug target(s), was used to evaluate possible biological targets of $83 \mathrm{~b} 1$ in cells [26]. The possible predicted protein targets with promising ligand-protein binding are shown in Table 2. These two targets were found to be complementary to $83 \mathrm{~b} 1$, with the highest complementary score based on their molecular structures according to the ChEMBL medicinal chemistry database indicating that they are protein-tyrosine phosphatase $1 \mathrm{C}$ and PPAR $\delta$. Another docking program in molecular docking server was utilized to determine the binding affinity of $83 \mathrm{~b} 1$ to its predicted target, PPAR $\delta$ (Fig. 4). The free binding energy of 83b1 to PPAR $\delta$ is $-7.41 \mathrm{kcal} / \mathrm{mol}$ (Fig. $4 \mathrm{~A}$ ), which shows a more stable and stronger binding than that between PPAR $\delta$ with its natural ligand, arachidonic acid that the free binding energy of arachidonic acid to PPAR $\delta$ was estimated to be $-5.66 \mathrm{kcal} / \mathrm{mol}$ (Fig. 4B).

\section{Effects of $83 \mathrm{~b} 1$ on the mRNA expression of COX-2 in ESCC cell lines}

Based on the prediction of PPAR $\delta$ as possible targets of $83 \mathrm{~b} 1$ from the molecular docking analysis, qPCR was conducted to determine the down-regulating effect of $83 \mathrm{~b} 1$ on COX-2 mRNA expression in four of the ESCC cell lines (KYSE-150, KYSE-450, SLMT-1, and HKESC-4). As previously described, the four ESCC cell lines were seeded for 24 hours and three concentrations of $83 \mathrm{~b} 1(5,10$, and $20 \mu \mathrm{g} / \mathrm{mL})$ were used to treat the cells before harvest. RT-PCR was performed to obtain the cDNA for qPCR to determine the expression of COX-2 mRNA with specific primers. As shown in Fig. 5, the expression of COX-2 mRNA in all four ESCC cell lines was significantly reduced after treatment with 83b1 $(\mathrm{p}<0.05, \mathrm{p}<0.01$, and $\mathrm{p}<0.001$ vs. untreated control, $\mathrm{n}=4)$.

\section{Effects of $83 \mathrm{~b} 1$ on $\mathrm{PGE}_{2}$ production in ESCC cell lines}

ELISA was performed to estimate the suppressing effects of $83 \mathrm{~b} 1$ on $\mathrm{PGE}_{2}$ production in the three ESCC cell lines (KYSE-150, KYSE-450, and SLMT-1). As mentioned above, the three ESCC cell lines were seeded for 24 hours, then treated with $83 \mathrm{~b} 1$ at three different concentrations $(5,10$, and 
A

KYSE-150

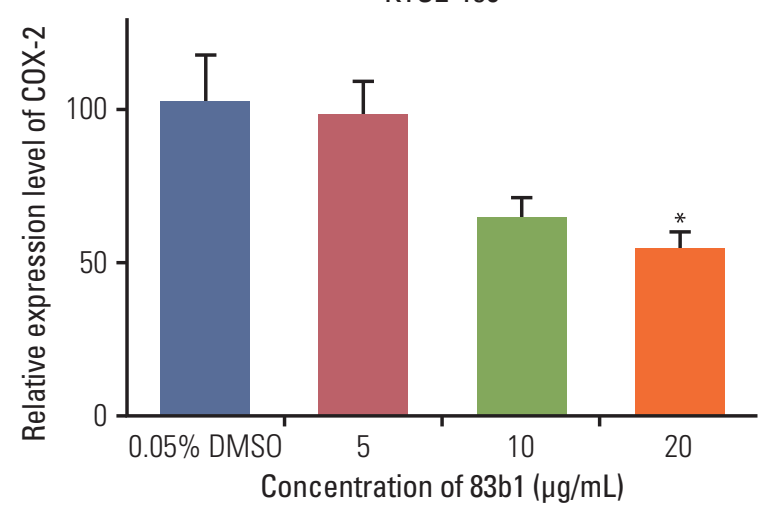

C

SLMT-1

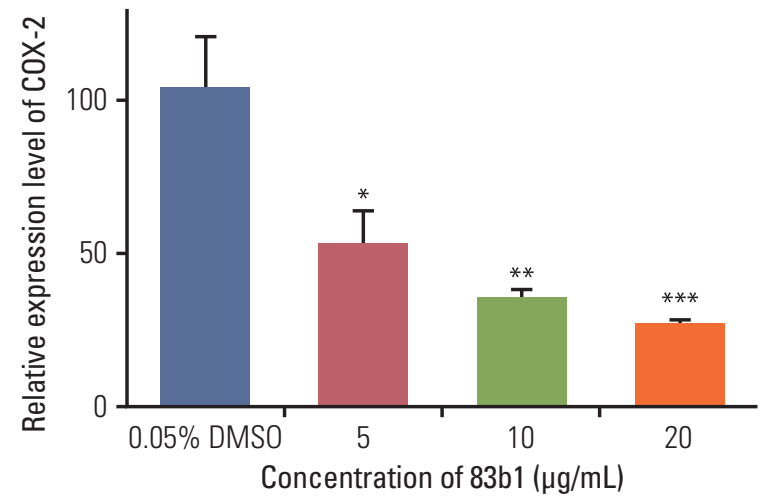

KYSE-450

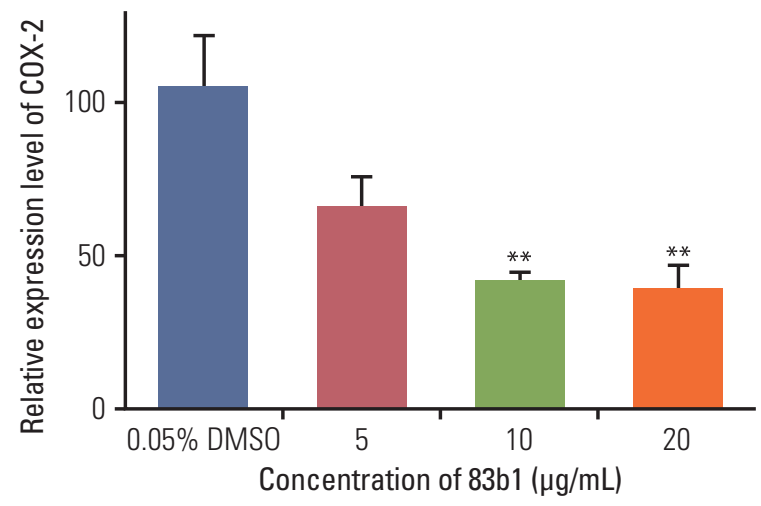

D

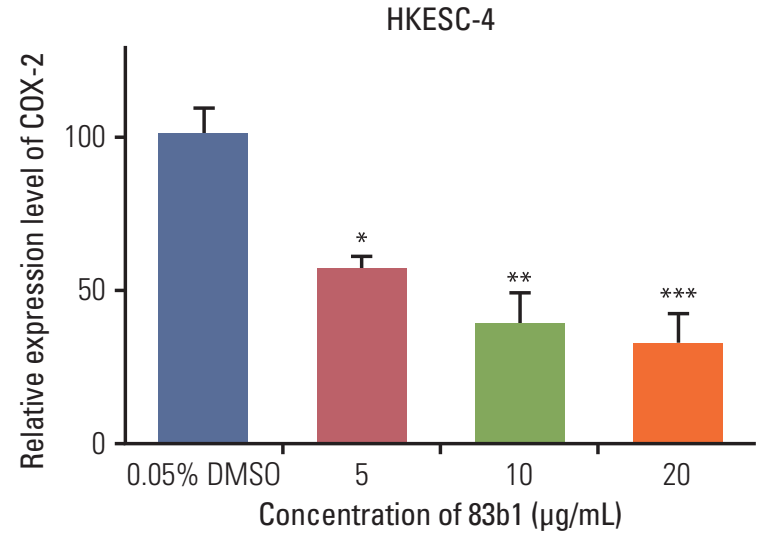

Fig. 5. The down-regulating effects of $83 \mathrm{~b} 1$ on cyclooxygenase 2 (COX-2) mRNA expression in KYSE-150 (A), KYSE-450 (B), SLMT-1 (C), and HKESC-4 (D). DMSO, dimethylsulfoxide. ${ }^{*} \mathrm{p}<0.05,{ }^{* *} \mathrm{p}<0.01$, and ${ }^{* * *} \mathrm{p}<0.001$ vs. untreated control, $\mathrm{n}=4$.

$20 \mu \mathrm{g} / \mathrm{mL}$ ) for 48 hours before the medium was collected for the assay. As shown in Fig. 6, 83b1 significantly down-regulated the production of $\mathrm{PGE}_{2}$ in all three ESCC cell lines at the respective doses $(\mathrm{p}<0.01, \mathrm{p}<0.001 \mathrm{vs}$. untreated control, $n=4)$.

\section{In vivo anti-tumor effect of $83 \mathrm{~b} 1$ on nude-mice xenograft with KYSE-450}

Athymic nude mice xenografted with the human KYSE450 ESCC cell line were used to test the in vivo anti-tumor effect of 83b1.

As shown in Fig. 7, $83 \mathrm{~b} 1$ significantly inhibited the tumor growth in mice when administered at $10 \mathrm{mg} / \mathrm{kg} /$ day relative to the vehicle controls. On day 19, the xenografts of the nude mice showed a significant reduction in tumor size after daily treatment with $83 \mathrm{~b} 1$. Overall, the results showed that $83 \mathrm{~b} 1$ effectively suppressed tumor growth in vivo ( $\mathrm{p}<0.001$ vs. control, $\mathrm{n}=5$ ).

\section{Discussion}

Natural compounds have been shown to have great potential in pharmaceutical applications. The greatest advantage of these compounds over traditional anti-cancer medicines is that they show much weaker cytotoxicity against normal cells because of their target-specificity. Actually, most existing anti-cancer drugs show very strong inhibitory effects against different kinds of tumors, but also trigger a series of side effects, some of which might be severe. Therefore, chemically modified natural compounds show great potential for 
A

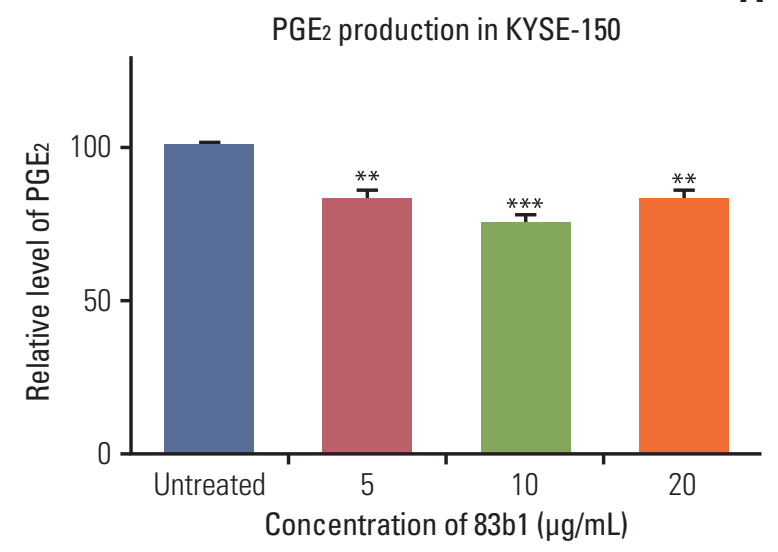

C

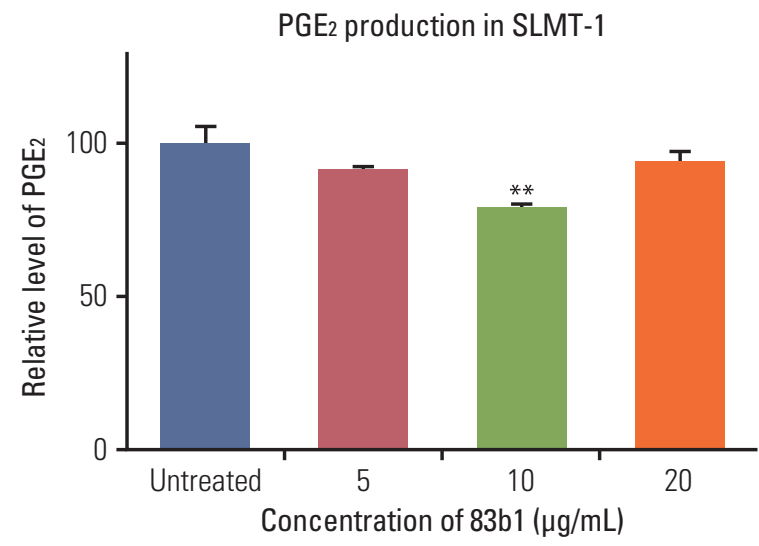

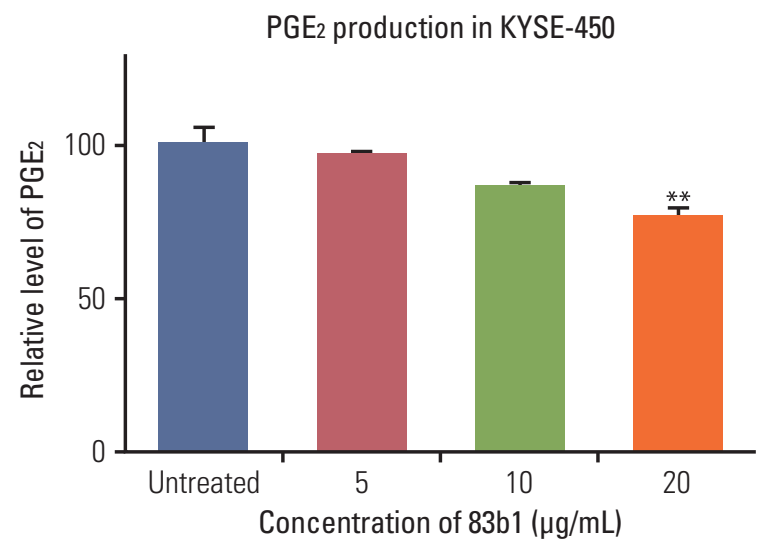

Concentration of $83 \mathrm{~b} 1(\mu \mathrm{g} / \mathrm{mL})$

Fig. 6. The down-regulating effects of $83 \mathrm{~b} 1$ on prostaglandin $\mathrm{E}_{2}\left(\mathrm{PGE}_{2}\right)$ production in KYSE-150 (A), KYSE-450 (B), and SLMT-1 (C). ${ }^{* *} \mathrm{p}<0.01,{ }^{* * *} \mathrm{p}<0.001$ vs. untreated control, $\mathrm{n}=4$.

use in disease therapies. Chemically modified quinolinederivatives have wide pharmaceutical power as therapeutic agents, and $83 \mathrm{~b} 1$ is a quinoline-derivative that has been shown to exert significant anti-tumor effects against ESCC with low cytotoxicity toward non-tumor cells.

In this study, 83b1 showed significantly greater anti-tumor effects against a series of ESCC cell lines relative to the widely used anti-cancer drug, CDDP, with much lower cytotoxicity against nontumor cells. It is an important criterion that anti-cancer drugs are able to suppress cancer growth selectively while they are not provoking damaging effects on normal cells.

Possible targets of $83 \mathrm{~b} 1$ were determined by molecular docking analysis, which revealed that it has a high binding preference to compete with the natural ligand to target PPAR $\delta$, which has been known as an oncoprotein. The functions of PPAR $\delta$ in COX-2 and COX-2-derived $\mathrm{PGE}_{2}$ produc- tion have been described, and the involvement of COX-2 and $\mathrm{PGE}_{2}$ in tumorigenesis in the ESCCs has been widely reported in many studies. Accordingly, it is important to see the effects of $83 \mathrm{~b} 1$ on the production of COX-2 and COX2derived PGE 2 .

Our results showed that $83 \mathrm{~b} 1$ can significantly down-regulate COX-2 mRNA expression in ESCC cell lines. Moreover, the production of COX-2-derived $\mathrm{PGE}_{2}$ in ESCC cell lines was also significantly reduced by treatment with $83 \mathrm{~b} 1$. Therefore, it is possible that $83 \mathrm{~b} 1 \mathrm{can}$ antagonize its possible target PPAR $\delta$ and hence suppress cancer growth through down-regulation of COX-2 and $\mathrm{PGE}_{2}$ production. The in vivo study also showed that $83 \mathrm{~b} 1$ can significantly suppress tumors in animals within 19 days, and that tumors inside of nude mice almost disappeared.

Overall, this study comprehensively described the functions and effects of $83 \mathrm{~b} 1$ on ESCC cell lines. The findings of 


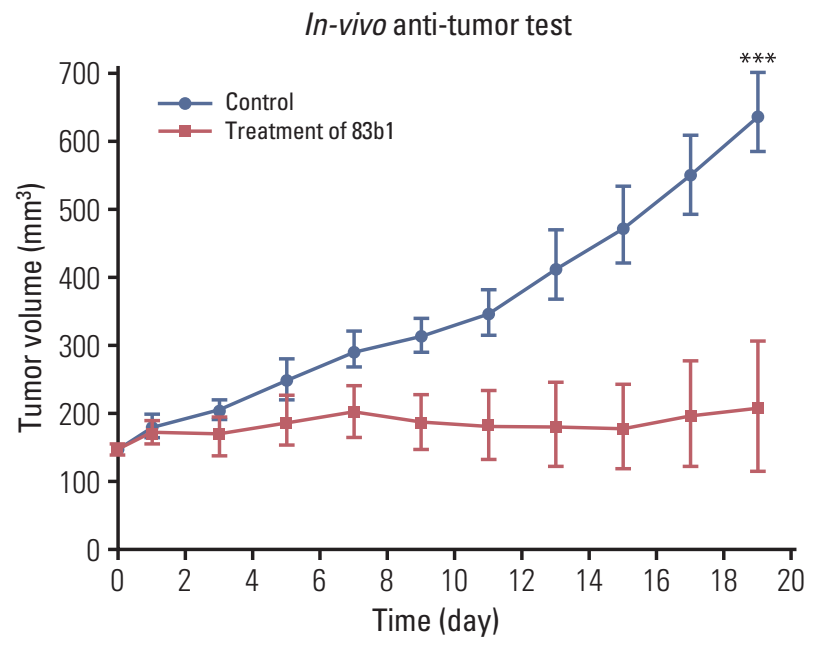

Fig. 7. Tumor xenografts in athymic nude mice derived from KYSE- 450 were treated with $10 \mathrm{mg} / \mathrm{kg} /$ day of $83 \mathrm{~b} 1$ or $6 \%$ polyethylene glycol (PEG) control through intraperitoneal injection. $83 \mathrm{~b} 1$ significantly reduced the tumor volume on the 19 th day. ${ }^{* * *} \mathrm{p}<0.001$ vs. control, $\mathrm{n}=5$.

this study also revealed the potential use of chemically modified natural compounds in disease therapy.

\section{Conclusion}

Chemically modified quinoline derivatives were recently shown to inhibit tumor growth through different kinds of mechanisms by interacting with various targets $[5,10]$. Here, we demonstrated that a novel quinoline derivative, 83b1, has strong inhibitory effects on tumor growth with less toxicity in non-tumor cell lines and nude mice xenograft models. The predicted target PPAR $\delta$ of $83 \mathrm{~b} 1$ has been widely reported as a cancer-promoting protein ubiquitously overexpressed in different types of cancer tissues [26]. We found that $83 \mathrm{~b} 1 \mathrm{can}$ target PPAR $\delta$, resulting in downregulation of COX-2 mRNA expression and reduced production of $\mathrm{PGE}_{2}$. The results presented herein will greatly advance development of novel drugs for cancer therapy by targeting PPAR $\delta$.

\section{Electronic Supplementary Material}

Supplementary materials are available at Cancer Research and Treatment website (http:// www.e-crt.org).

\section{Conflicts of Interest}

Conflict of interest relevant to this article was not reported.

\section{Acknowledgments}

This study was supported by the Lo Ka Chung Foundation Fund (a/c: ZE20 and 954P), Central Research Grants (a/c: G-UC11 and G-YM35) offered by the Hong Kong Polytechnic University and the MOU signed with Hong Kong Baptist University and Griffith University.

\section{References}

1. Jemal A, Bray F, Center MM, Ferlay J, Ward E, Forman D. Global cancer statistics. CA Cancer J Clin. 2011;61:69-90.

2. Qiu H, Mao Y, Gu Y, Zhu J, Wang Y, Zeng J, et al. The potential of photodynamic therapy to treat esophageal candidiasis coexisting with esophageal cancer. J Photochem Photobiol B. 2014;130:305-9.

3. Sakaeda T, Yamamori M, Kuwahara A, Nishiguchi K. Pharmacokinetics and pharmacogenomics in esophageal cancer chemoradiotherapy. Adv Drug Deliv Rev. 2009;61:388-401.

4. Souza RF, Shewmake K, Beer DG, Cryer B, Spechler SJ. Selective inhibition of cyclooxygenase-2 suppresses growth and induces apoptosis in human esophageal adenocarcinoma cells. Cancer Res. 2000;60:5767-72.

5. Chan SH, Chui CH, Chan SW, Kok SHL, D. C, Tsoi MYT, et al. Synthesis of 8-hydroxyquinoline derivatives as novel antitumor agents. ACS Med Chem Lett. 2013;4:170-4.

6. Michael JP. Quinoline, quinazoline and acridone alkaloids. Nat Prod Rep. 1998;15:595-606.

7. Kumar S, Bawa S, Gupta H. Biological activities of quinoline derivatives. Mini Rev Med Chem. 2009;9:1648-54.

8. Tharayil N, Bhowmik P, Alpert P, Walker E, Amarasiriwardena D, Xing B. Dual purpose secondary compounds: phyto- 
toxin of Centaurea diffusa also facilitates nutrient uptake. New Phytol. 2009;181:424-34.

9. Jeon JH, Lee CH, Lee HS. Antimicrobial activities of 2-methyl8-hydroxyquinoline and its derivatives against human intestinal bacteria. J Korean Soc Appl Biol Chem. 2009;52:202-5.

10. Lam KH, Gambari R, Lee KK, Chen YX, Kok SH, Wong RS, et al. Preparation of 8-hydroxyquinoline derivatives as potential antibiotics against Staphylococcus aureus. Bioorg Med Chem Lett. 2014;24:367-70.

11. Takayama O, Yamamoto H, Damdinsuren B, Sugita Y, Ngan $\mathrm{CY}, \mathrm{Xu} \mathrm{X}$, et al. Expression of PPARdelta in multistage carcinogenesis of the colorectum: implications of malignant cancer morphology. Br J Cancer. 2006;95:889-95.

12. Xu L, Han C, Wu T. A novel positive feedback loop between peroxisome proliferator-activated receptor- $\delta$ and prostaglandin E2 signaling pathways for human cholangiocarcinoma cell growth. J Biol Chem. 2006;281:33982-96.

13. Fournier T, Tsatsaris V, Handschuh K, Evain-Brion D. PPARs and the placenta. Placenta. 2007;28:65-76.

14. Hla T, Neilson K. Human cyclooxygenase-2 cDNA. Proc Natl Acad Sci U S A. 1992;89:7384-8.

15. Dimberg J, Hugander A, Sirsjo A, Soderkvist P. Enhanced expression of cyclooxygenase- 2 and nuclear beta-catenin are related to mutations in the APC gene in human colorectal cancer. Anticancer Res. 2001;21:911-5.

16. Zimmermann KC, Sarbia M, Weber AA, Borchard F, Gabbert HE, Schror K. Cyclooxygenase-2 expression in human esophageal carcinoma. Cancer Res. 1999;59:198-204.

17. Sun WH, Sun YL, Fang RN, Shao Y, Xu HC, Xue QP, et al. Expression of cyclooxygenase-2 and matrix metalloproteinase9 in gastric carcinoma and its correlation with angiogenesis. Jpn J Clin Oncol. 2005;35:707-13.

18. Sun WH, Zhu F, Chen GS, Su H, Luo C, Zhao QS, et al. Blockade of cholecystokinin-2 receptor and cyclooxygenase-2 synergistically induces cell apoptosis, and inhibits the proliferation of human gastric cancer cells in vitro. Cancer Lett. 2008;263:302-11.

19. Greenhough A, Smartt HJ, Moore AE, Roberts HR, Williams AC, Paraskeva C, et al. The COX-2/ PGE2 pathway: key roles in the hallmarks of cancer and adaptation to the tumour microenvironment. Carcinogenesis. 2009;30:377-86.
20. Lam KH, Xu L, Feng L, Fan QH, Lam FL, Lo WH, et al. Highly enantioselective iridium-catalyzed hydrogenation of quinoline derivatives using chiral phosphinite H8-BINAPO. Adv Synth Catal. 2005;347:1755-8.

21. Tang JC, Wan TS, Wong N, Pang E, Lam KY, Law SY, et al. Establishment and characterization of a new xenograftderived human esophageal squamous cell carcinoma cell line SLMT-1 of Chinese origin. Cancer Genet Cytogenet. 2001;124: 36- 41 .

22. Shimada Y, Imamura M, Wagata T, Yamaguchi N, Tobe T. Characterization of 21 newly established esophageal cancer cell lines. Cancer. 1992;69:277-84.

23. Deng W, Tsao SW, Guan XY, Lucas JN, Si HX, Leung CS, et al. Distinct profiles of critically short telomeres are a key determinant of different chromosome aberrations in immortalized human cells: whole-genome evidence from multiple cell lines. Oncogene. 2004;23:9090-101.

24. Zhang H, Jin Y, Chen X, Jin C, Law S, Tsao SW, et al. Cytogenetic aberrations in immortalization of esophageal epithelial cells. Cancer Genet Cytogenet. 2006;165:25-35.

25. Tang WK, Chui CH, Fatima S, Kok SH, Pak KC, Ou TM, et al. Inhibitory effects of Gleditsia sinensis fruit extract on telomerase activity and oncogenic expression in human esophageal squamous cell carcinoma. Int J Mol Med. 2007;19:953-60.

26. Kim MO, Hong ES, Chai JY, Leem JM, You IY, Kim WD, et al. Concurrent FP (5-fluorouracil, cisplatin) chemoradiotherapy for patients with esophageal cancer. Cancer Res Treat. 2003; 35:330-4.

27. Keiser MJ, Roth BL, Armbruster BN, Ernsberger P, Irwin JJ, Shoichet BK. Relating protein pharmacology by ligand chemistry. Nat Biotechnol. 2007;25:197-206.

28. Bikadi Z, Hazai E. Application of the PM6 semi-empirical method to modeling proteins enhances docking accuracy of AutoDock. J Cheminform. 2009;1:15.

29. Zhang D, Wood CE. Neuronal prostaglandin endoperoxide synthase 2 responses to oxygen and glucose deprivation are mediated by mitogen-activated protein kinase ERK1/2. Brain Res. 2005;1060:100-7.

30. Jin M, Li L, Xu C, Wen Y, Zhao M. Estrogenic activities of two synthetic pyrethroids and their metabolites. J Environ Sci (China). 2010;22:290-6. 